Revista Brasileira de Agricultura Irrigada v.12, no .7, p. 3108 - 3117, 2018

ISSN 1982-7679 (On-line)

Fortaleza, CE, INOVAGRI - http://www.inovagri.org.br

DOI: $10.7127 /$ rbai.v12n700982

Protocolo 982.18 - 30/06/2018 Aprovado em 21/02/2019

\title{
CRESCIMENTO E DESENVOLVIMENTO DE PLANTAS JOVENS DE IPÊ-AMARELO SUBMETIDAS A DIFERENTES REGIMES HÍDRICOS
}

Nayane da Silva Souza ${ }^{1}$, Heráclito Eugênio Oliveira da Conceição ${ }^{2}$, Maria Kalyane Farias da Silva ${ }^{3}$, Larissa Jaina da Silva de Oliveira ${ }^{4}$, Wilson José de Mello e Silva Maia ${ }^{5}$, Michel Sauma Filho ${ }^{6}$

\begin{abstract}
RESUMO
O déficit hídrico pode afetar a fotossíntese tanto por efeitos no comportamento dos estômatos como não estomático ou metabólico e dependendo da intensidade e duração, os danos causados por este podem ser reversíveis ou não, em muitos casos provocando a morte da planta. Conhecer as necessidades hídricas de determinada cultura é crucial para o sucesso na produção. Assim, o objetivo do presente trabalho foi avaliar o crescimento e desenvolvimento de plantas jovens de ipê-amarelo submetidas a diferentes regimes hídricos. O experimento constituiu de quatro tratamentos: irrigação diária (d), irrigação a cada 3 dias (3d), irrigação a cada 7 dias (7d) e irrigação a cada 10 dias (10d), com 4 repetições e 2 plantas, em um delineamento inteiramente casualizado (DIC). Nos tratamentos 3d, 7d e 10d procedia-se a re-irrigação durante $24 \mathrm{~h}$, com vistas a elevar a umidade do solo para próximo da capacidade de campo. As médias de crescimento e de produção foram comparadas pelo teste de Tukey a 5\% de probabilidade através do software Assistat 7.7. Por meio dos resultados obtidos foi possível concluir que o estresse hídrico empregado não influenciou no crescimento da planta e na área foliar, porém influenciou diretamente na produção de massa seca durante o período de estresse. $O$ fator de correção foliar de 0,76 encontrado no presente trabalho, permite sua utilização na correção e determinação da área foliar de qualquer cultura da espécie.
\end{abstract}

Palavras-chave: Estresse. Irrigação. Matéria seca.

\section{GROWTH AND DEVELOPMENT OF YOUNG PLANTS OF IPÊ-YELLOW SUBMITTED TO DIFFERENT WATER REGIMES}

1 Mestranda em Fitopatologia, Universidade Federal de Lavras, Lavras, Minas Gerais, Brasil. E-mail: nayanesouza42@gmail.com

2 Professor Adjunto, Universidade Federal Rural da Amazônia, Capitão Poço, Pará, Brasil. E-mail: heraclito.eugenio@ufra.edu.br

3 Mestranda em Produção Vegetal, Universidade Norte Fluminense Darcy Ribeiro, Campos de Goytacazes, Rio de Janeiro, Brasil. E-mail: kalyanefar@gmail.com

4 Mestranda em Genética e Melhoramento de Plantas, Universidade Norte Fluminense Darcy Ribeiro, Campos de Goytacazes, Rio de Janeiro, Brasil. E-mail: larissajaina@gmail.com

5 Professor Adjunto I, Universidade Federal Rural da Amazônia, Capitão Poço, Pará, Brasil. E-mail: wilsonmellomaia@gmail.com

6 Professor Assistente, Universidade Federal Rural da Amazônia, Capitão Poço, Pará, Brasil. E-mail: michel.sauma@ufra.edu.br 


\begin{abstract}
The water deficit can affect photosynthesis both by effects on stomatal and non-stomatal or metabolic behavior, and depending on the intensity and duration, damage caused by it may be reversible or not, in many cases causing plant death. Knowing the hydric needs of determined crop is crucial to the success in productionThus, of objective the present work was to evaluate the growth and development of young plants of ipê-yellow submitted to different regimes of water, constituting four treatments: daily irrigation (d), irrigation each 3 days (3d), irrigation each 7 days (7d) and irrigation each 10 days (10d), with 4 repetitions and 2 plants, in a completely randomized design (DIC). In the $3 \mathrm{~d}, 7 \mathrm{~d}$ and $10 \mathrm{~d}$ treatments, the soil was re-irrigated for $24 \mathrm{~h}$, aiming at raising the soil moisture to near field capacity. The averages of growth and production were compared by the Tukey test at $5 \%$ probability using the Assistant software 7.7. By means of the results obtained it was possible to conclude that water stress applied did not influence growth of plant and the leaf area, however, it directly influenced dry matter production during stress period. The leaf correction factor in 0,76 found in present work allows its use in it correction and determination of it leaf area any crop in it species.
\end{abstract}

Keywords: Stress. Irrigation. Dry matter.

\section{INTRODUÇÃO}

O ipê-amarelo, Tabebuia serratifolia (Vahl), conhecido em diferentes regiões vulgarmente como pau-d'arco-amarelo, ipêpardo, ipê do cerrado, é uma espécie arbórea pertencente à família Bignoniaceae, encontrada em quase todo território brasileiro (LORENZI, 2008).

É uma planta decídua, heliofita, característica de floresta pluvial densa, sendo também dispersa nas formações secundárias. É uma planta com preferência em solos bem drenados situados nas encostas. Sua dispersão é geralmente uniforme e sempre muito esparsa (LORENZZI, 2008). A floração é sincronizada, rápida e anual, e no Pará, esta ocorre entre os meses de julho a outubro, que acontece durante ou após a queda completa das folhas e, a frutificação ocorre entre os meses de outubro e novembro (GUSMÃO, 2012).

Diferentes espécies têm desenvolvido mecanismos para enfrentar a baixa quantidade de água no substrato (LAMBERS et al., 1998), através de modificações na morfologia externa, na citologia, na fisiologia e na histologia da planta (DICKISON, 2000). A deficiência hídrica pode conduzir ao fechamento estomático e ao movimento de folhas, mecanismos que evitam perda de água, através do fechamento estomático, a fim de evitar a formação de bolhas no xilema (TSUDA; TYREE, 2000; COCHARD, 2002).

Segundo Farias et al., (2007), secas severas, na fase vegetativa, reduzem o crescimento da planta, diminuindo a área foliar, podendo em muitos casos causar a morte da planta. De um modo geral, o estresse hídrico provoca alterações como a redução do potencial hídrico foliar, o fechamento estomático, a diminuição da taxa fotossintética, a redução da sua parte aérea, a aceleração da senescência, abscisão das folhas, dentre outras (FERRARI et al., 2015), que dependendo da intensidade e duração, os danos causados podem ser reversíveis ou não, comprometendo a integridade funcional da planta (DA MATTA; RAMALHO, 2006).

A resposta mais proeminente das plantas ao déficit hídrico, segundo Taiz e Zeiger, (2017), consiste no decréscimo da produção da área foliar, da aceleração da senescência e da abscisão das folhas. Desse modo, conhecer o IAF (Índice de Área Foliar) e a AF (Área Foliar), pode ser de grande utilidade em diversas práticas culturais, como densidade de plantio, adubação, entre outros, além de ser uma medida bastante utilizada nos estudos agronômicos e fisiológicos, envolvendo o crescimento vegetal (RIANO et al., 2004).

Objetivou-se, nesse trabalho avaliar o crescimento e desenvolvimento de plantas 
jovens de ipê-amarelo submetidas a diferentes regimes de estresse hídrico.

\section{MATERIAL E MÉTODOS}

O experimento foi realizado, no período de 26/08 a 06/11/2015, em condições de estufa agrícola da Universidade Federal Rural da Amazônia/Campus Capitão Poço, localizado entre as coordenadas geográficas de $1^{\circ} 44^{\prime} 47^{\prime \prime} \mathrm{S}$

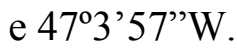

Foram utilizadas plântulas de ipêamarelo, com aproximadamente três pares de folhas verdadeiras, colhidas em uma área sob a projeção da copa de árvores adultas localizadas na zona rural do município de Capitão Poço PA. As plântulas foram transplantadas para sacos de polietileno com capacidade para $4 \mathrm{~kg}$ de solo, preenchidas com um Latossolo Amarelo, textura média e aclimatadas, em condições de estufa agrícola, durante 30 dias, em seguida, repicadas individualmente para sacos de polietileno com capacidade para 25 $\mathrm{kg}$, com dimensões de $30 \mathrm{~cm}$ de largura por 60 $\mathrm{cm}$ de comprimento. Após 60 dias nessas condições, iniciaram-se a imposição dos tratamentos de estresse hídrico por meio de restrição da irrigação.

$\mathrm{O}$ experimento consistiu de quatro tratamentos: irrigação diária (d), irrigação a cada 3 dias (3d), irrigação a cada 7 dias (7d) e irrigação a cada dez dias (10d), com 4 repetições e 2 plantas por unidade experimental. Os tratamentos foram distribuídos em delineamento experimental inteiramente casualizado, em esquema fatorial 4 x 6 (quatro regimes hídricos e seis tempos de avaliações, respectivamente).

Não foi calculado a quantidade de água utilizada na irrigação de cada planta, sendo fornecida água até que esta não infiltrasse mais no solo. Exceto o tratamento d, os demais tratamentos recebiam água em seus respectivos dias e eram re-irrigadas após 24 horas para o restabelecimento da umidade de solo. A duração da imposição dos tratamentos de estresse hídrico durou 75 dias. Os efeitos dos tratamentos foram avaliados por meio das seguintes variáveis: altura da planta (AP, em $\mathrm{cm}$ ), diâmetro do caule à $5 \mathrm{~cm}$ do solo (DC, em $\mathrm{cm})$, número de folhas (NF), estas avaliadas a cada 15 dias; conteúdo relativo de água no limite máximo de estresse hídrico (CRAm, em $\%$ ), conteúdo relativo de água após 24 horas de re-irrigação (CRAr, em \%), umidade do solo no limite máximo de estresse hídrico (USm, em $\%$ ) e umidade do solo após 24 horas de reirrigação dos tratamentos de estresse hídrico (USr, em \%) e pesos de massas secas de folha (MSF), caule (MSC) e da raiz (MSR), avaliadas aos 75 dias após a imposição do estresse hídrico.

No caso da área (AF), inicialmente procedeu-se à determinação do fator de correção foliar $(\mathrm{Fc})$, por meio de método destrutivo gravimétrico utilizando-se o peso da massa de matéria seca da folha e sua relação com a área foliar de cinco folíolos por folha em uma amostra de duas plantas por tratamento.

Para estimar a área foliar, foi utilizada a média de pesos e média da área de cinco recortes de papel com dimensões de $10 \mathrm{~cm}$ x 10 $\mathrm{cm}$, após terem sido colocados em estufa a 70 ${ }^{\circ} \mathrm{C}$ por três horas. A área foliar foi determinada pela equação 1 encontrando-se o fator de correção médio de 0,76 .

$$
A F=\frac{M \times A f}{m}
$$

em que:

$\mathrm{AF}$ : área foliar em $\mathrm{cm}^{2}$;

m: massa da folha em $\mathrm{g}$;

Af: área do quadrado de papel $\mathrm{em} \mathrm{cm}^{2}$; $\mathrm{m}$ : massa do quadrado de papel em $\mathrm{g}$.

Assim, a área foliar pôde ser determinada pela equação 2 , sendo calculada para cada folha e encontrando-se a área corrigida.

$$
A F=0,76 \times(C \times L)
$$

em que:

0,76: é o fator de correção;

C e L: o comprimento e a largura da folha, respectivamente.

Para o cálculo da área foliar da planta (AfP em $\mathrm{cm}^{2}$ ), utiliza-se a equação 3, sendo acrescentado à equação a variável NF correspondente ao número de folhas da planta. 


$$
A f P=[N F(F C(C \times L))]
$$

O conteúdo relativo de água no limite máximo de estresse hídrico (CRAm, em \%) e o conteúdo relativo de água após $24 \mathrm{~h}$ de reirrigação dos tratamentos de estresse hídrico (CRAr, em \%), foram determinados por meio do método de Slavick (1974).

A umidade do solo no limite máximo de estresse hídrico (Usm, em \%) e a umidade do solo após $24 \mathrm{~h}$ de re-irrigação dos tratamentos de estresse hídrico (Usr, em \%), foram obtidas pelo método padrão de estufa (KLEIN, 2008), usando-se amostras de solo da camada de 0 a $20 \mathrm{~cm}$ de profundidade por meio de trado. Os pesos das massas de matérias secas, em g/planta, da folha (MSF), do caule (MSC) e da raiz (MSR), determinados segundo metodologia de Benincasa, 2004.

Os dados obtidos foram submetidos a análise de variância e, quando se detectava efeito significativo, as médias foram comparadas pelo teste de Tukey a 5\% de probabilidade através do software Assistat 7.7 (SILVA; AZEVEDO, 2016).

\section{RESULTADOS E DISCUSSÕES}

O comportamento das umidades de solo no limite máximo de estresse hídrico (Usm) e após 24 h de reirrigação dos tratamentos de estresse hídrico (Usr), está representado na Figura 1.

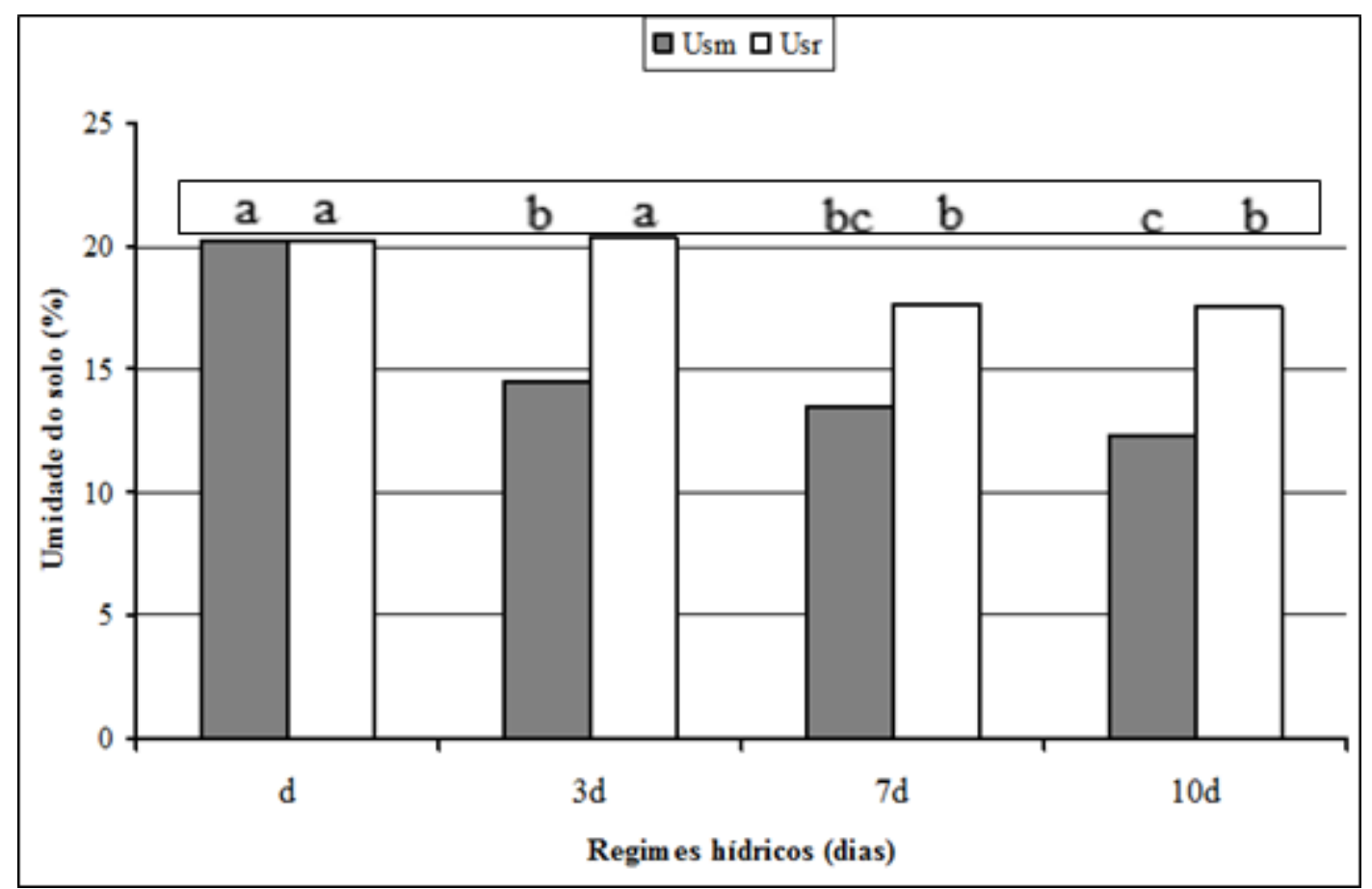

Figura 1. (A) Umidade do solo no máximo de estresse hídrico (Usm) e após 24 h de re-irrigação (Usr).

A Usm decresce continuamente, com a imposição dos tratamentos de estresse hídrico, e alcançam valores mínimos de $14,52 \%$, $13,45 \%$ e $12,28 \%$ de umidade de solo, nos tratamentos $\mathrm{d} 3, \mathrm{~d} 7 \mathrm{e} \mathrm{d} 10$, equivalentes a $71,74 \%, 66,45 \%$ e $60,67 \%$ do valor obtido no tratamento d. Após 24 horas de re-irrigação, verificou-se que os tratamentos d7 e d10 não recuperaram totalmente a Usr (Figura 1).

Os tratamentos submetidos às maiores intensidades de estresse hídrico, tratamentos d7 e d10, não recuperaram plenamente o valor inicial de umidade de solo quando comparados ao tratamento d (controle) após 24 horas de reirrigação.

Para Taiz e Zeiger (2017), a deficiência hídrica no solo por longos períodos, é um dos fatores que mais interferem no desenvolvimento das culturas agrícolas, o que acarreta em perturbações fisiológicas e morfológicas que prejudicam o pleno desenvolvimento das plantas. 
O conteúdo relativo de água nas folhas no limite máximo de estresse hídrico (CRAm) se manteve constante nos tratamentos d e $3 d$ (Figura 2).

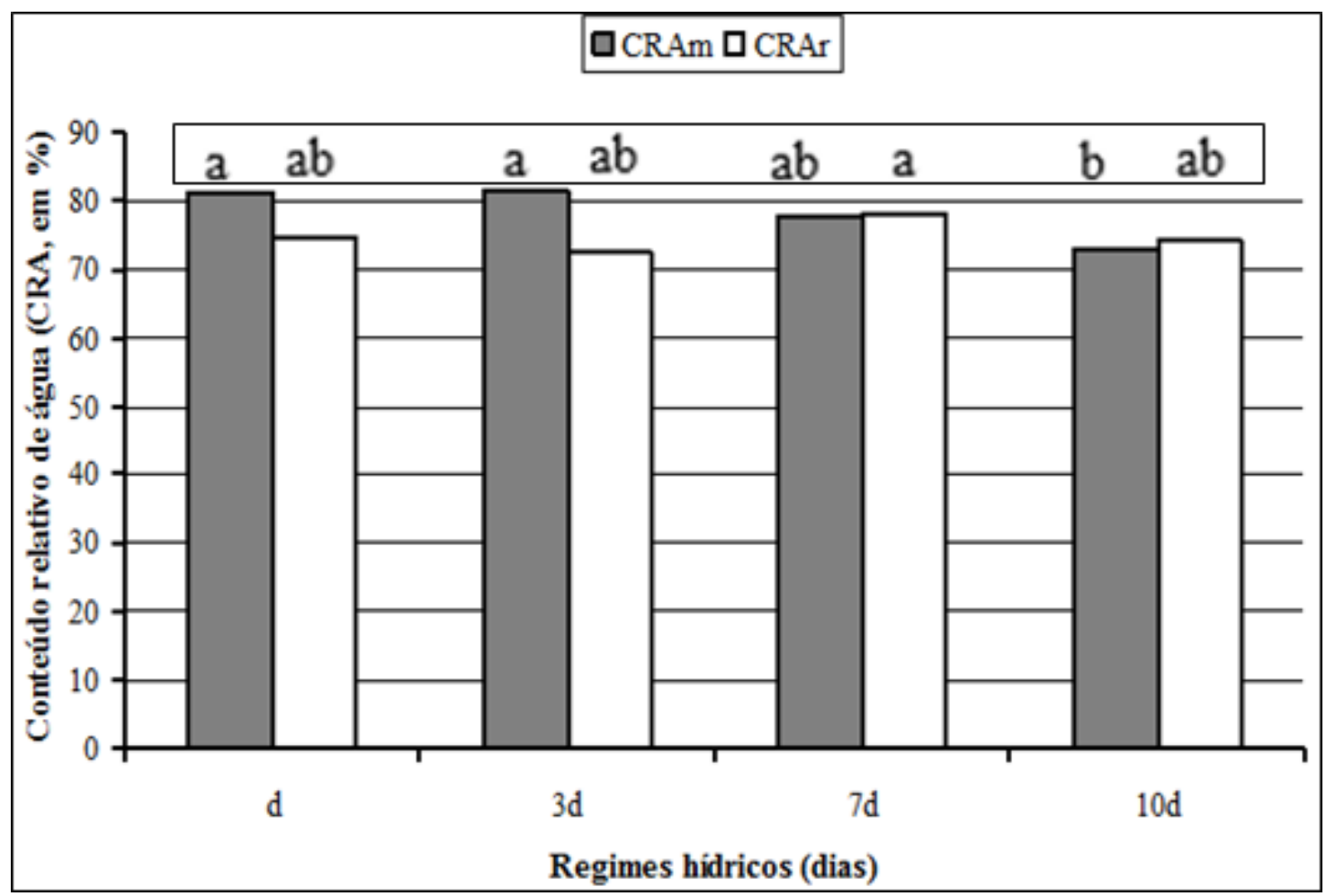

Figura 2. Conteúdo relativo de água no limite máximo de estresse hídrico (CRAm) e após 24 h de re-irrigação (CRAr) determinados em plantas jovens de ipê-amarelo, após 75 dias de tratamento.

O conteúdo relativo de água após a reirrigação (CRAr) se manteve constante no tratamento $7 \mathrm{~d}$ e aumentou cerca de $2 \%$ no tratamento 10d. Já nos tratamentos d e 3d decresceram quando comparados ao CRAm, de $80 \%$ para cerca de 75 e $73 \%$ respectivamente.

Resultados semelhantes foram encontrados por Mariano et al., (2009) que em estudo com Myracrodruon urundeuva Fr. All., observaram que as plantas submetidas à irrigação diária apresentaram um maior conteúdo relativo de água $(85 \%)$ do que as plantas submetidas ao déficit hídrico (48\%).

Para as variáveis AP e DC, as análises dos dados revelaram efeitos significativos para os fatores isolados.

A área foliar (AF) não foi afetada significativamente $(\mathrm{p}<0,05)$ pelos tratamentos de déficit hídrico. O diâmetro do caule (DC) dos tratamentos $10 \mathrm{~d}$ e $3 \mathrm{~d}$ acompanharam a tendência de crescimento do tratamento $\mathrm{d} e, \mathrm{o}$ tratamento $7 \mathrm{~d}$ foi reduzido significativamente $(\mathrm{P}<0,05)$ (Tabela 1).

Tal resultado deve-se possivelmente ao fato de que, segundo Taiz e Zeiger (2017), as plantas, bioquimicamente, alteram seu metabolismo de várias maneiras, para se acomodar ao estresse ambiental, o que pode explicar o fato de as plantas submetidas a um maior período de estresse, tratamento $10 \mathrm{~d}$, terem desenvolvido mecanismos que acarretaram em uma maior expansão caulinar. Ainda na Tabela 1, é possível verificar que o padrão de crescimento e desenvolvimento de plantas jovens de ipê-amarelo, nessas condições, avaliados por meio dessas variáveis, apresentou respostas diferenciadas, indicando que a redução da disponibilidade de água no solo de até 10 dias não reduziu a $\mathrm{AF}$, isso significa que, estatisticamente o período de estresse de 10 dias não diferiu dos outros tratamentos para a área foliar. 
Tabela 1. Altura da Planta (AP), Diâmetro do Caule a $5 \mathrm{~cm}$ do solo (DC), Número de Folhas (NF), Área Foliar (AF) de plantas jovens de ipê amarelo submetidas a diferentes regimes hídricos

\begin{tabular}{cccc}
\hline \multirow{2}{*}{ Tratamentos } & \multicolumn{3}{c}{ Variáveis $^{1}$} \\
\cline { 2 - 4 } & AP $(\mathrm{cm})$ & DC $(\mathrm{cm})$ & AF $\left(\mathrm{cm}^{2}\right)$ \\
\hline $\mathrm{d}$ & $169,65 \mathrm{a}$ & $1,26 \mathrm{ab}$ & $352,23 \mathrm{a}$ \\
$3 \mathrm{~d}$ & $171,92 \mathrm{a}$ & $1,21 \mathrm{ab}$ & $376,80 \mathrm{a}$ \\
$7 \mathrm{~d}$ & $154,55 \mathrm{~b}$ & $1,17 \mathrm{~b}$ & $355,80 \mathrm{a}$ \\
$10 \mathrm{~d}$ & $148,13 \mathrm{~b}$ & $1,30 \mathrm{a}$ & $376,14 \mathrm{a}$ \\
\hline & 161,06 & 1,24 & 365,24 \\
CV $(\%)$ & 8,57 & 10,19 & 9,56 \\
DMS & 10,48 & 10,48 & 73,31 \\
\hline
\end{tabular}

${ }^{1}$ Médias seguidas de mesma letra, em cada coluna, não diferem entre si, pelo teste de Tukey a 5\% de probabilidade.

Alguns autores encontraram decréscimo em taxas de razão de área foliar em plantas cultivadas sob déficit hídrico (PEIXOTO et al., 2006) com sustentação em estudos observados por Benincasa (2004), que segundo esta autora, o comportamento está associado à redução da área foliar útil a partir de uma determinada fase sob déficit hídrico, sugerindo que, para a variável AF do presente estudo ser afetada negativamente, seria necessário submeter estas plantas a um maior intervalo de tempo sob estresse hídrico. Para Figueiroa et al., (2004) a relação umidade de solo e o tamanho alcançado pelas folhas, está relacionado ao aumento de área foliar total, explicado pela boa disponibilidade hídrica. Assim, em solos secos são produzidas folhas pequenas, o que contribui para reduzir o aquecimento dos tecidos foliares e a transpiração na estação mais quente (SCALON et al., 2011).

Quando se

analisa

o comportamento de AP (Figura 3A) e DC (Figura 3B) em função do tempo de avaliações, o melhor ajuste dessas variáveis pode ser explicado por meio de equações de $2^{\circ}$ grau.

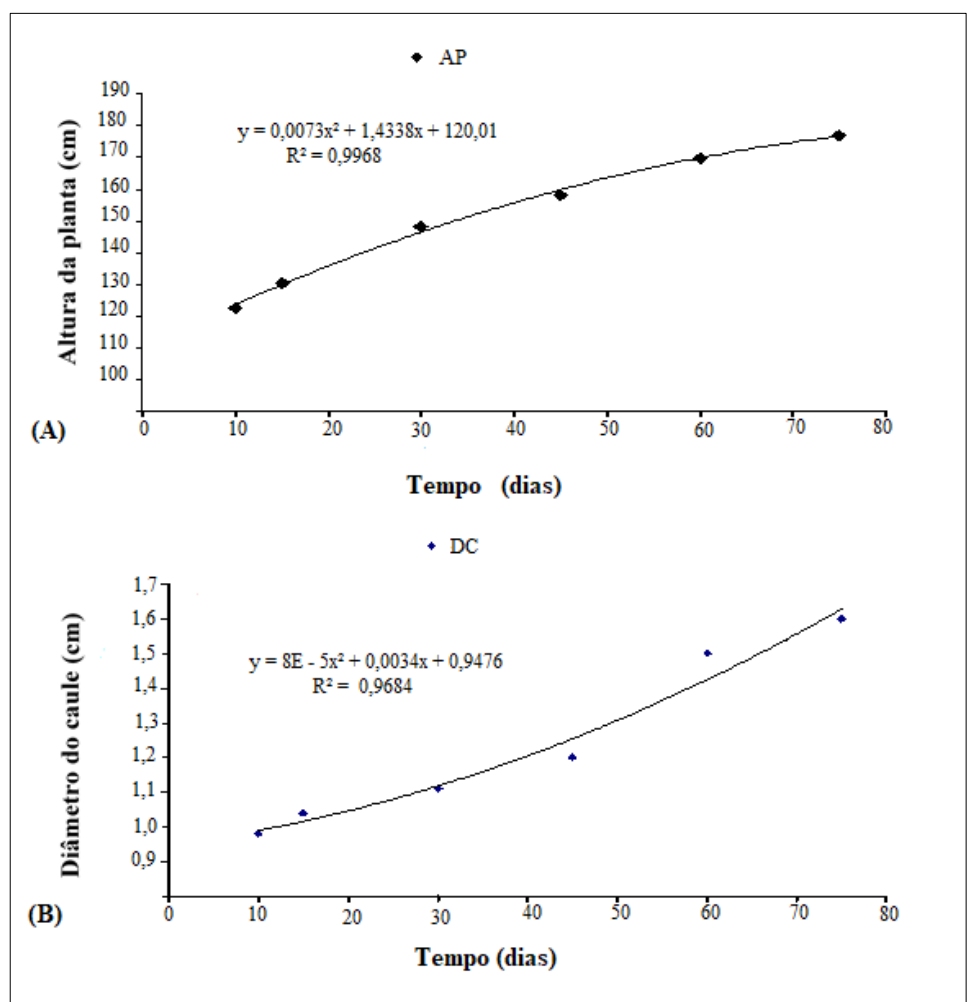

Figura 3. Efeitos do tempo de avaliação sobre à altura da planta (AP) (A) e o diâmetro do caule (DC) (B), em plantas de ipê-amarelo submetidas a diferentes regimes hídricos, durante 75 dias. 
Martins et al., (2008), demonstraram em estudo com eucalipto que as variáveis altura da planta e número de folhas começam a ser afetadas imediatamente após o início da aplicação da deficiência hídrica. Alguns autores relacionam o fato de variáveis como altura da planta, número de folhas e diâmetro do caule serem afetadas pelo déficit hídrico no solo. Esse comportamento indica a ocorrência da diminuição na turgescência das células antes do fechamento estomático, suficiente para afetar o metabolismo e causar redução no crescimento e desenvolvimento das plantas. Para diâmetro do caule, Gonçalves et al.,
(2000) consideram diâmetro adequado para plantas jovens de espécies florestais ideal de 5 e $10 \mathrm{~mm}$. Um dos fatores que pode explicar um maior incremento de diâmetro caulinar ser superior no tratamento com maior período de estresse, pode ser devido aos mecanismos de sobrevivência desenvolvido pelas plantas quando submetidas a tal situação (TAIZ; ZEIGER, 2017).

Na Figura 4 estão representados o estudo da interação RH x TA (Regime Hídrico x Tempo de Avaliação) para a variável NF representados por equações de $2^{\circ}$ grau ascendente.

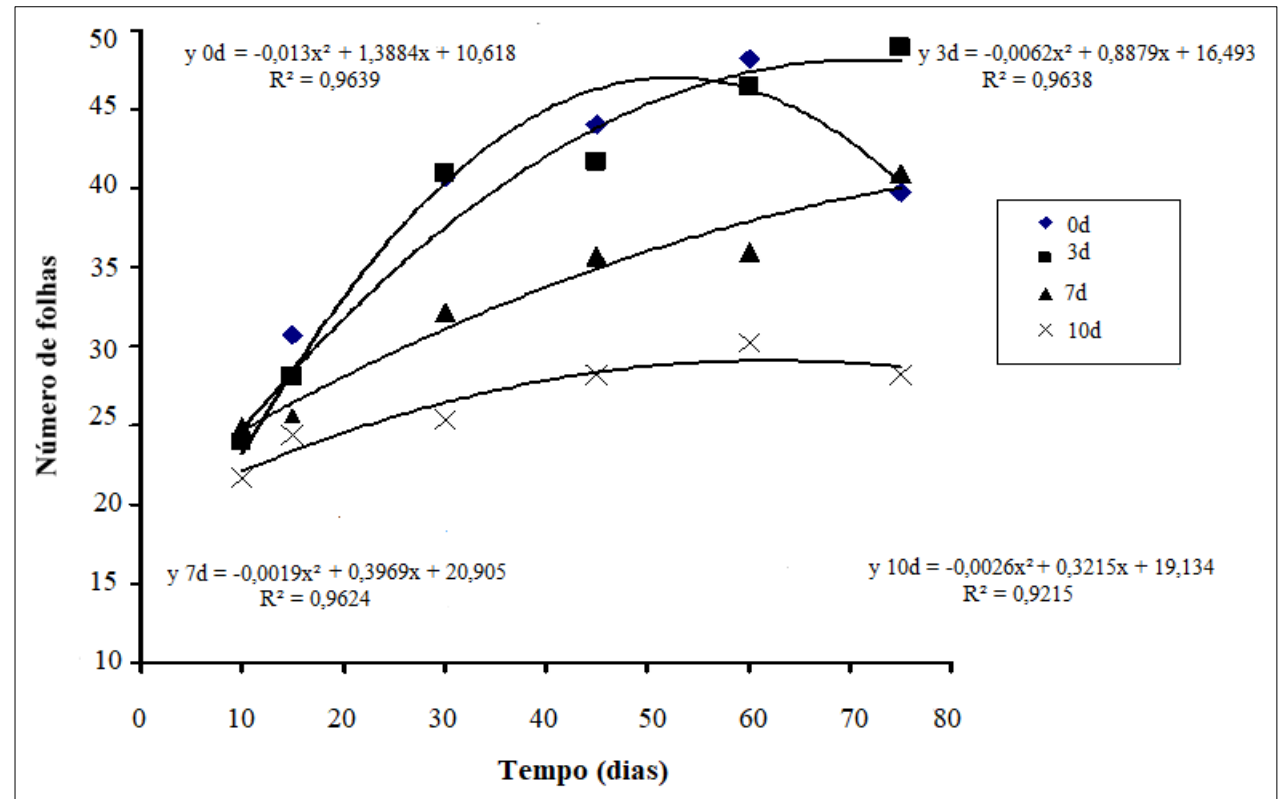

Figura 4. Efeitos da interação regimes hídricos $x$ tempo de avaliação sobre o número de folhas (NF), em plantas de ipê-amarelo submetidas a diferentes regimes hídricos, durante 75 dias.

O número de folhas, durante todo o período de estresse, foi menor no tratamento 10d, no qual era irrigado a cada 10 dias. Esse resultado pode ser explicado através da estratégia de sobrevivência que plantas desenvolvem quando são submetidas a longos períodos de estresse hídrico, evitando a perda de água por transpiração, além de reduzir a área foliar e consequentemente diminuir a quantidade de matéria seca das folhas. Em trabalho com mudas de eucalipto, Schwider et al., (2013) obtiveram redução do número de folhas em plantas que receberam uma menor quantidade de água. Em termos, o tratamento $10 \mathrm{~d}$ recebeu menor quantidade de água durante o período de estresse, explicando assim, o menor número de folhas.

As maiores produções de massas secas de raiz (MSR) e da parte aérea (MSPA) foram obtidas no tratamento d, o qual era irrigado diariamente, entretanto, não diferiu dos tratamentos d3 e d7 (Tabela 2). 
Tabela 2. Massa Seca da Raiz (MSR), Massa Seca do Caule (MSC), Massa Seca da Folha (MSF), Massa Seca Parte Aérea (MSPA), Massa Seca Total (MST) de plantas jovens de ipê amarelo submetidas a diferentes regimes hídricos.

\begin{tabular}{cccccc}
\hline \multirow{2}{*}{ Tratamentos } & \multicolumn{5}{c}{ Variáveis $(\mathrm{g})$} \\
\cline { 2 - 6 } & MSR & MSC & MSF & MSPA & MST \\
\hline $\mathrm{d}$ & $41,54 \mathrm{a}$ & $106,88 \mathrm{a}$ & $73,59 \mathrm{a}$ & $180,47 \mathrm{a}$ & $222,01 \mathrm{a}$ \\
$3 \mathrm{~d}$ & $34,55 \mathrm{ab}$ & $83,55 \mathrm{ab}$ & $75,30 \mathrm{a}$ & $158,85 \mathrm{a}$ & $193,40 \mathrm{~b}$ \\
$7 \mathrm{~d}$ & $33,64 \mathrm{ab}$ & $59,03 \mathrm{bc}$ & $50,75 \mathrm{~b}$ & $109,78 \mathrm{~b}$ & $143,42 \mathrm{c}$ \\
$10 \mathrm{~d}$ & $23,40 \mathrm{~b}$ & $47,98 \mathrm{c}$ & $44,15 \mathrm{~b}$ & $92,48 \mathrm{~b}$ & $115,88 \mathrm{c}$ \\
\hline & 33,28 & 74,36 & 60,95 & 135,40 & 168,18 \\
CV $(\%)$ & 22,54 & 20,60 & 22,02 & 17,15 & 15,58 \\
DMS & 15,75 & 32,17 & 28,20 & 23,20 & 18,72 \\
\hline
\end{tabular}

Médias seguidas de mesma letra em cada coluna não diferem entre si, pelo teste de Tukey, em nível de 5\% de probabilidade.

Scalon et al., (2011), em seus estudos com mutambo (Guazuma ulmifolia Lam.), também obtiveram maior produção de massa seca de raiz em plantas com maior disponibilidade de água, mesmo não havendo diferença no comprimento das raízes. Segundo Hsiao e Xu (2000), a continuidade do crescimento radicular, sob condições de menor disponibilidade hídrica, depende da manutenção de uma pressão de turgor mínima nas células, que seja suficiente para permitir o alongamento e crescimento da parede celular. Esses autores relatam que quando a disponibilidade de água é reduzida nas raízes, ocorre em diversas espécies um rápido ajuste osmótico, que auxilia no restabelecimento da pressão de turgor, o que permite a manutenção do alongamento celular.

As produções de massas de matérias secas das folhas (MSF) e do caule (MSC) dos tratamentos $7 \mathrm{~d}$ e $10 \mathrm{~d}$, foram reduzidas significativamente. A massa seca total (MST) desses tratamentos seguiu a mesma tendência de MSF e MSC, sendo, ainda, seguido do tratamento $3 \mathrm{~d}$, quando comparado com o tratamento controle (d).

Em geral, a produção de massa de matéria seca dos órgãos de ipê-amarelo, foi reduzida diferente e progressivamente, de acordo com o aumento da intensidade dos regimes hídricos, destacando-se a MSF e a MSC, como as mais sensíveis.

Resultados semelhantes foram relatados por Cabral et al., (2004), que encontraram diferenças significativas em relação a matéria seca das folhas, massa seca da parte aérea e total das plantas submetidas a estresse hídrico. Kumar e Sharma, (2009), observaram acúmulo de massa de matéria seca na parte aérea em relação às raízes de plantas de Vigna radiata, cultivadas em campo e submetidas ao estresse hídrico. Freire et al., (2012), observaram em estudos com gliricídia submetida a estresse hídrico, redução significativa no acúmulo de massa da parte aérea, provavelmente em decorrência da baixa produção de fotoassimilados causada pela redução na disponibilidade de água para as plantas (MATSUI; SINGH, 2003).

\section{CONCLUSÕES}

O estresse hídrico de 7 e 10 dias causou redução no crescimento de plantas jovens de ipê-amarelo, porém, não influenciou estatisticamente em sua a área foliar (AF). A área foliar de qualquer cultura da espécie pode ser estimada com o produto do coeficiente 0,76 pelo comprimento, largura e número de folhas.

\section{REFERÊNCIAS BIBLIOGRÁFICAS}

BENINCASA, M. M. P. Análise de Crescimento de Plantas (noções básicas). Jaboticabal. FUNEP. 2004. 42p.

CABRAL, E. L.; BARBOSA, D. C. A.; SIMABUKURO, E. A. Crescimento de plantas 
jovens de Tabebuia aurea (Manso) Benth. \& Hook. f. ex S. Moore submetidas a estresse hídrico. Acta Botanica. Brasilica. 18(2): 241251. 2004.

COCHARD, H. A technique for measuring xylem hydraulic conductance under high negative pressures. Blackwell Science Ltd, Plant, Cell and Environment, 25, 815-819. 2002.

DA MATTA, F. M.; RAMALHO, J. D. C. Impacts of drought and temperature stress on coffee physiology and production: a review. Brazilian Journal of Plant Physiology. v.18, n.1, p. 9-21. http://dx.doi.org/10.1590/S167704202006000100006

DICKISON, W.C. Integrative Plant Anatomy. USA, Academic Press. 533p. 2000

FARIAS, J. R. B; NEPOMUCENO, A. L; NEUMAIER, N. Ecofisiologia da Soja. Londrina: Embrapa CNPSO, 2007. 9p. (Circular Técnica, No 48).

FERRARI, E.; PAZ, A.; SILVA, A. C. Déficit hídrico no metabolismo da soja em semeaduras antecipadas no Mato Grosso. Nativa, Sinop, v.3, $\mathrm{n}^{\circ}$ 01, p. 66-77, 2015. http://dx.doi.org/10.14583/2318-

7670.v03n01a12

FIGUEIROA, M. F.; BARBOSA, D.C.C.; SIMABUKURO, C.A. Crescimento de plantas jovens de Myracrodruon urundeuva Allemão (Anacardiaceae) sob diferentes regimes hídricos. Acta Botânica Brasilica, São Paulo v. 18, n. 3, p. 1-14, jul./set. 2004. http://dx.doi.org/10.1590/S0102-

3062004000300015

FREIRE, A. L. O.; LEÃO, D. A. S.; MIRANDA, J. R. P. Acúmulo de massa seca e de nutrientes em gliricídia em resposta ao estresse hídrico e a doses de fósforo. Seminário de Ciências Agrárias, Londrina, v. 33, n. 1, p. 19-26, 2012. http://dx.doi.org/10.5433/1679-

0359.2012v33n1p19.
GUSMÃO, M. T. A; FERREIRA, G. C; OHASHI, S. T. Espécies florestais nativas e exóticas da Amazônia Oriental. Universidade Federal Rural da Amazônia, 2012. 86 p.:

GONÇALVES, J. L. M.; SANTERELLI, E.G.; NETO, S. P. M.; MANARA, M. P. Produção de mudas de espécies nativas: substrato, nutrição, sombreamento e fertilização. In: GONÇALVES, J. L. M.; BENEDETTI, V. (Eds.) Nutrição e fertilização florestal. Piracicaba: ESALQ/USP, p.309-350, 2000.

HSIAO, T. C.; XU, L. K. Sensitivity of growth of roots versus leaves to water stress: biophysical analysis and relation to water transport. Journal of Experimental Botany, Oxford, v.51, p.1595-1616, 2000. https://doi.org/10.1093/jexbot/51.350.1595

KLEIN, V. A. Física do solo. Passo Fundo. Ed. Universidade de Passo Fundo, 2008. 212p.

KUMAR, A.; SHARMA, K. D. Physiological responses and dry matter partitioning of summer mungbean (Vigna radiata L.) genotypes subjected to drought conditions. Journal of Agronomy and Crop Science, Berlin, v. 195, n. 4, p. 270-277, 2009. https://doi.org/10.1111/j.1439-

037X.2009.00373.x

LAMBERS, H.; CHAPIN, F.S. \& PONS, T.L. Plant Physiological Ecology. New York, Springer-Verlag. 1998, 540p.

LORENZI, H. Árvores brasileiras: manual de identificação e cultivo de plantas arbóreas nativas do Brasil. $5^{\circ}$ ed. Instituto Plantarum de Estudos da Flora, 2008.

MARIANO, K.R.; BARRETO, L.S.; SILVA, H.B. A.; NEIVA, G.K.P.; AMORIM, S. Fotossíntese e tolerância protoplasmática foliar em myracrodruon urundeuva FR. ALL. submetida ao déficit hídrico. Revista Caatinga, vol. 22, núm. 1, enero-marzo, 2009, pp. 72-77. Disponível em $:<$ http://www.redalyc.org/articulo.oa?id=2371 17625010> ISSN 0100-316X 
MARTINS, F. B.; STRECK, N. A.; SILVA, J. C.; MORAIS, W. W.; SUSIN, F.; NAVROSKI, M. C.; VIVIAN, M. A. Deficiência hídrica no solo e seu efeito sobre transpiração, crescimento e desenvolvimento de mudas de duas espécies de eucalipto. Revista Brasileira de Ciência do Solo. Vol. 32. n. 3. Viçosa, $2008 . \quad$ http://dx.doi.org/10.1590/S010006832008000300037

MATSUI, T.; SINGH, B. B. Roots characteristics in cowpea related to drought tolerance at the seedling stage. Experimental Agriculture, Cambridge, v. 39, n. 1, p. 29-38, 2003.

https://doi.org/10.1017/S0014479703001108

PEIXOTO, C.P.; CERQUEIRA, E.C.; SOARES FILHO, W.S.; DE CASTRO NETO, M.T.; LEDO, C.A.S.; MATOS, F.S.; OLIVEIRA, J.G. Análise de crescimento de diferentes genótipos de citros cultivados sob déficit hídrico. Revista Brasileira de Fruticultura, Jaboticabal-SP, v. 28, n. 3, p. 439-443, dezembro 2006. http://dx.doi.org/10.1590/S0100-

29452006000300022

RIANO, H.N.M.; ARCILA, P.J.; JARAMILLO, R.A.; CHAVES, C.B. Acumulación de materia seca y extracción de TAIZ, L. ZEIGER, E. Fisiologia e Desenvolvimento Vegetal. 6. ed. Porto Alegre. Artmed, 2017. nutrimentos por Coffea arábica L. cv. Colombia em tres localidades de la zona cafetera central. Cenicafé, Bogotá, v. 55, n. 4, p. 265-276, 2004.

SCALON, S.P.Q.; MUSSURY, R. M.; EUZÉBIO, V. L. M.; KODAMA, F. M.; KISSMANN, C. Estresse hídrico no metabolismo e crescimento inicial de mudas de mutambo (Guazuma ulmifolia Lam.). Ciência Florestal, Santa Maria, v. 21, n. 4, p. 655-662, out.-dez. 2011. http://dx.doi.org/10.5902/198050984510.

SLAVICK, B. Methods of studyng plant water relations. New York, Springer-Verlag. 1974, 449 p.

SCHWIDER, Y.S.; PEZZOPANE, J.E.M.; CÔRREA, V.B.; TOLEDO, J.V.; XAVIER, T.M.T. Efeito do deficit hídrico sobre o crescimento de eucalipto em diferentes condições microclimáticas. Enciclopédia Biosfera, Goiânia, v.9, n.16, p. 888-900. 2013.

SILVA, F. de A. S; AZEVEDO, C. A. V. de. The Assistat Software Version 7.7 and its use in the analysis of experimental data. African Journal of Agricultural Research, v.11, n.39, p3733-3740, 2016.

TSUDA, M.; TYREE, M. T. Plant hydraulic conductance measured by the high pressure flow meter in crop plants. Journal of Experimental Botany, 51: 823- 828, 2000. 